\title{
Can semi-automated image cytometry on induced sputum become a screening tool for lung cancer?
}

\author{
Evaluation of quantitative semi-automated sputum cytometry on radon- and \\ uranium-exposed workers
}

\author{
W. Marek*, N. Kotschy-Lang", A. Muti*, Ch. Köhler*, L. Nielsen*, Th. Topalidis ${ }^{\Uparrow}$, Z. Atay ${ }^{\Uparrow}$, \\ J.A. Nakhosteen*
}

\begin{abstract}
Can semi-automated image cytometry on induced sputum become a screening tool for lung cancer? W. Marek, N. Kotschy-Lang, A. Muti, Ch. Köhler, L. Nielsen, Th. Topalidis, Z. Atay, J.A. Nakhosteen. C) ERS Journals Ltd 2001.

ABSTRACT: The correlations between semi-automated sputum cytometry (ASC), conventional cytology and the final diagnosis was investigated in industrially-exposed workers. Slides of sputum samples from 201 former uranium miners with silicosis, 100 patients with asbestosis, 103 workers resected for lung cancer, and 200 controls $(50 \%$ smokers), were stained using the Papanicolaou (Pap) method and the Feulgen reaction with thionin. Cytometry was performed using the Cyto-Savant automated system.

Atypical nuclei were found in $\mathbf{7 2}$ of $\mathbf{4 0 4}$ patient samples, 327 samples were normal and five were inadequate for ASC analysis. Thirteen tumours (Pap IV, Pap V) and 11 cases of severe dysplasia were identified by cytology. Lung cancer was confirmed in 20 patients. Compared to the final diagnosis of lung cancer, the sensitivity of ASC was $75 \%$ (15 out of 20) and specificity $89.8 \%(520$ out of 579$)$. The results represent a diagnostic efficiency of $89.3 \%$. The combination of ASC with cytology increased sensitivity to $80 \%$ (16 out of 20 ) without significant loss of specificity $(89.7 \%$ or 523 out of 581).

In this investigation of a limited number of patients with occupational radon or asbestos exposure, semi-automated sputum cytometry appears to be sensitive and reliable for the detection of malignant changes in the tracheobronchial mucosa. Together with conventional cytology, it would be reasonable to test the validity of the combined methods in a large-scale feasibility study of early lung cancer detection. Eur Respir J 2001; 18: 942-950.
\end{abstract}

\begin{abstract}
*Research Institute for Diagnosis and Treatment of Early Lung Cancer (RIDTELC), Dept of Pulmonary Medicine and Respiratory Allergology, Augusta-Teaching-Hospital, Bochum; ${ }^{\#}$ Berufsgenossenschaftliche Klinik für Berufskrankheiten Falkenstein/Vogtland; "Zytologisches Institut Atay und Topalidis, Hannover, Germany.
\end{abstract}

Correspondence: W. Marek, Research Institute for Diagnosis and Treatment of Early Lung Cancer (RIDTELC), Dept of Pulmonary Medicine and Respiratory Allergology, Augusta-TeachingHospital, Bergstr. 26, D-44971 Bochum, Germany.

Fax: 492345172463

Keywords: Asbestos exposure, cytology, lung cancer, radon exposure, semiautomated sputum cytometry, sputum induction

Received: March 102000

Accepted after revision July 52001
Semi-automated image cytometry represents a new sensitive method for the quantitative analysis of nuclear structure and deoxyribonucleic acid (DNA) content of exfoliated airway epithelial cells [1]. Together with autofluorescence bronchoscopy [2], it is a promising new technology potentially aiding diagnosis of early-stage lung cancer, and renewing interest in lung-cancer screening .

The undisputed effects of smoking on lung cancer can be multiplied by exposure in the workplace, most prominently to ionizing radiation or asbestos dust [3]. Epidemiological studies have confirmed that lung cancer is increased among uranium miners in the USA [4] and other countries due to ionizing irradiation. In 1995 and 1996, 761 notifications of occupational lung disease induced by ionizing radiation were registered in Germany. In 1994, 1,200 cases of asbestos-induced tumours were registered. As in any cancer, the prognosis of occupation-related cancer is likely to improve with effective screening, but this has proved to be an elusive goal in lung cancer. Multiple factors have contributed to the failure of earlier lung cancer screening trials [5-8] and a primary factor, by today's standards, was antiquated technology. Since 1995 at the Research Institute for Diagnosis and Treatment of Early Lung Cancer (RIDTELC), the authors have been intensively involved in the development and refinement of a number of promising methods for improving detection of early lung cancer, including sputum processing and analysis.

Automated sputum processing has become possible by the prototype Medical Application Robot Automation for Tissue Handling or Nuclei Separation (MARATHON-S), now in routine use for monolayer sputum preparations, stained for semi-automated sputum cytometry (ASC) and conventional cytology (CY). Specimen preparation has been improved and standardized by addition of $0.1 \%$ dithiothreitol (DTT) to the Saccomanno's preservative [9]. As a prelude to a large screening programme for detecting early lung cancer in high-risk individuals, semi-automated cytometry and cytology of induced sputa from uranium 
miners with silicosis and patients with asbestosis were performed. In addition, patients with resected lung cancer without known recurrence were included. The authors investigated the correlations of ASC and CY with the final diagnosis.

\section{Methods}

\section{Patients}

Three groups of patients were included, comprising individuals with silicosis, asbestosis, or undergoing follow-up following resected lung cancer. All were being seen for a regular checkup in a hospital, specializing in occupational lung disease (Berufsgenossenschaftliche Klinik Falkenstein in Thüringen, Germany). Sputum specimens were collected September 1996-December 1998, together with 100 samples from heavy smokers and 100 nonsmoking control subjects with no radon or asbestos exposure and with normal lung function. Patient data are summarized in table 1.

\section{Sputum induction}

Under the supervision of a respiratory therapist, sputum was induced by inhalation of 3\% saline aerosol, generated by a jet nebulizer (Pari, Starnberg, Germany) for $20 \mathrm{~min}$. The patients inhaled the aerosol via a mouthpiece, exhaling through the nose. The subjects were instructed to swallow saliva and to expectorate sputum, from the deeper airways only, into a $50-\mathrm{mL}$ vial filled with $25 \mathrm{~mL}$ Saccomanno'spreservative and $0.1 \%$, DTT $[9,10]$. The samples were labelled, posted on the same day and arrived at the laboratory 1-3 days later.

\section{Staining}

Sputum samples arriving at the lab in the Saccomanno-DTT solution were completely liquefied and could be treated like a blood smear for a monolayer preparation by the automated processor (MARATHON-S). After centrifugation for $15 \mathrm{~min}$ at $500 \times g$, the supernatant was decanted. Depending on the weight, the cell pellet was resuspended in 0.5-2.5 mL Saccomanno solution to obtain constant cell concentrations. Two drops of the cell suspension $(\sim 0.2 \mathrm{~mL})$ were applied to each of six slides, smeared like a blood sample, avoiding nuclear artefacts or distortion by using capillary forces only. The slides were air-dried overnight; two were stained according to Papanicolaou [11] for cytology, two according to a modified Feulgen reaction [12] for ASC, and the remaining two slides were kept for future reference. The two smears for ASC were dehydrated for $30 \mathrm{~min}$ in $96 \%$ ethanol, fixed for $45 \mathrm{~min}$ in Böhm-Sprenger solution and rinsed in distilled water. The purine bases were removed at room temperature $\left(20^{\circ} \mathrm{C}\right)$ by $45 \mathrm{~min}$ hydrolysis in $5 \mathrm{~N} \mathrm{HCl}$. The slides were stained for $60 \mathrm{~min}$ in saturated thionin solution and rinsed in sodiumbisulphite solutions. After dehydration in increasing alcohol concentrations and xylene, the specimens were cover-slipped using resin for permanent mounting.

\section{Cytology}

CY was performed independently of cytometry in Hannover and/or Bochum. Results were graded according to a modified Papanicolaou (Pap) classification using a score from Pap 0-Pap V [13]: Pap 0: nonrepresentative material, Pap I: normal cell/nuclear structure, Pap II: benign changes (mostly mild, moderate or severe signs of inflammation), Pap III: metaplastic changes, Pap IIID: dysplasia (mild, moderate, or severe), Pap IV: carcinoma in situ, (CIS), Pap V: some/numerous malignant cells, carcinoma most probable. In case of mild and moderate dysplasia, a second sputum sample was requested for confirmation of the results. In cases of severe dysplasia or higher grades, immediate investigations (endoscopy, chest radiography, etc.) were recommended.

\section{Semi-automated cytometry}

Quantitative cytometry was performed by an automated image cytometer (Cyto-Savant $\AA$, Oncometrics, Vancouver, Canada), which was developed in

Table 1. - Patients and control group data

\begin{tabular}{|c|c|c|c|c|c|}
\hline & $\begin{array}{l}\text { Silicosis, } \\
\text { group I }\end{array}$ & $\begin{array}{l}\text { Asbestosis, } \\
\text { group II }\end{array}$ & $\begin{array}{l}\text { Resected LC, } \\
\text { group III }\end{array}$ & $\begin{array}{l}\text { Smokers, } \\
\text { group IV }\end{array}$ & $\begin{array}{l}\text { Nonsmokers, } \\
\text { group V }\end{array}$ \\
\hline Subjects $n$ & 201 & 100 & 103 & 100 & 100 \\
\hline $\mathrm{M}: \mathrm{F}$ & 201:0 & $95: 5$ & 103:0 & $75: 25$ & $72: 28$ \\
\hline Age yrs & $68 \pm 5$ & $66 \pm 7$ & $67 \pm 6$ & $52 \pm 12$ & $53 \pm 15$ \\
\hline Cigarette consumption pack-yrs & $\begin{array}{l}27 \pm 12 \\
(\mathrm{n}=155)\end{array}$ & $\begin{array}{l}27 \pm 12 \\
(n=75)\end{array}$ & $\begin{array}{l}22 \pm 7 \\
(n=61)\end{array}$ & $34 \pm 24$ & \\
\hline Radon exposure yrs & $12 \pm 11$ & & $\begin{array}{l}15 \pm 13 \\
(n=76)\end{array}$ & & \\
\hline Time since last exposure yrs & $36 \pm 13$ & & $31 \pm 13$ & & \\
\hline Asbestos exposure yrs & & $24 \pm 12$ & $\begin{array}{l}23 \pm 12 \\
(\mathrm{n}=27)\end{array}$ & & \\
\hline Time since last exposure yrs & & $17 \pm 12$ & $15 \pm 8$ & & \\
\hline
\end{tabular}

Data are presented as mean \pm SEM unless otherwise stated. LC: lung cancer; M: male; F: female. 
Table 2. - Classification of semiautomated sputum cytometry results

\begin{tabular}{ll}
\hline Grade & \multicolumn{1}{c}{ Description } \\
\hline 0: inadequate & Too few diagnostic cells from the airways \\
I: benign & Normal nuclear structure, euploidy, 2cDI $<0.20$ \\
II: suspicious & Samples with $2 \mathrm{cDI}>0.20$ or 2cDI $<0.20$, but with suspicious \\
nuclei in the cell gallery with a DNA index of $1.25-2.5$ \\
III: highly suspicious & 2cDI $>0.20$ and abnormal nuclei in the cell gallery with a DNA index $>5 \mathrm{c}$
\end{tabular}

DNA index: deoxyribonucleic acid (DNA), amount of normal epithelial cells set to 1.0 equals normal diploid DNA content (2c); 2cDI: 2c-deviation index.

collaboration with British Columbia Cancer Agency in Vancouver [14]. The technology followed the recommendations of the Task Force on Standardization of Quantitative Methods in Diagnostic Pathology (ESACP) [15]. A specially designed trainable binary classifier for exfoliated cells of the lung [1, 16] was developed for the cytometer. A high-resolution CCD digital camera with 1.4 million pixels was used along with a $20 \times$ Plan-Apo microscope objective (Nikon, Tokyo, Japan), yielding a resolution of $0.34 \mu \mathrm{m}$. In addition to photometric DNA measurement, $>110$ nuclear features were calculated, quantifying chromatin distribution morphometrically for each nucleus [16].

The automated mode allowed $\leqslant 50$ slides daily to be screened unattended for a preset period of time (30 $\mathrm{min})$ or for a limited number of nuclei. In the present version, the cytometer identifies and analyses up to 50,000 objects in $30 \mathrm{~min}$. The authors collected and stored $\leqslant 2,000$ cells from each specimen $(1,000$ epithelial cells, 200 suspicious nuclei with a DNA index (DNA-amount of normal epithelial cells set to 1.0 equals normal diploid DNA content $(2 \mathrm{c}))>1.25$ and $<2.5$ and $\leqslant 100$ highly suspicious ones with a DNA index $>2.5$ ). Along with the epithelial cells, $\leqslant 200$ lymphocytes, polymorphonuclear and eosinophil granulocytes and 100 alveolar macrophages were collected. The standard value for the integrated optical density of epithelial cells was 110 . Using 20-times magnification and a matrix of $1.4 \times 10^{6}$ pixels (screen resolution $1,246 \times 1,026$ points) results in a pixel size of $0.34 \mu \mathrm{m}$. A typical epithelial nucleus with $10-12 \mu \mathrm{m}$ diameter contains nearly 1,000 pixels. The size of a nucleus is derived from the total number of pixels. The grey-values between white and black are divided into 256 grey levels. The sum of all grey levels of the pixels of a nucleus represents the amount of DNA.

For each of the 2,000 cells, digital values of all features were calculated and stored. Coordinates of all cells were stored; suspicious nuclei could be revisited interactively. The DNA-amount of normal epithelial nuclei, referred to as the 2 c-value or euploidy value, derived from a representative group of lymphocytes, is $2 \mathrm{c} \pm 0.25 \mathrm{c}$ and corresponds to a coefficient of variance of $12.5 \%$. Three parameters were calculated from DNA values of the epithelial nuclei: the rate $(\%)$ of $5 \mathrm{c}$-exceeding nuclei (5cER), the 2c-deviation index $(2 \mathrm{cDI})$ and the malignancy grade $(\mathrm{MG})$ as the logarithmically transformed 2cDI [15]. The 2cDI represents the sum of squares of the differences between the DNA-amount of the single nuclei and the mean value derived from all the epithelial nuclei collected, divided by the number of collected nuclei. Both parameters, 2cDI and 5cER, closely correlate with grade of malignancy. The 5cER is the rate $(\%)$ of aneuploid nuclei with a DNA-amount $>5 \mathrm{c}$. These are different from normal separating mitotic nuclei. Nuclei are called euploid if their DNA-amount is in the range $2 \mathrm{c} \pm 0.25 \mathrm{c}$. The $2 \mathrm{cDI}$ is defined as the sum of all squared deviations of the DNA-amount of all epithelial cells $\left(\mathrm{c}_{\mathrm{i}}\right)$ from the mean value $(2 \mathrm{c})$ divided by the number of cells. This value is equivalent to the mean square from the deviation of the mean diploid-value [17]. Optically abnormal nuclei from the cell galleries were registered even if quantification of DNA content was unremarkable.

This procedure allows quantification of the whole spectrum of malignancy with the help of a simple score. Following the recommendations of the ESACP [15] for quantitative cytometry, the authors used the categories 0 , I, II and III (table 2).

\section{Statistics}

The sensitivity and specificity of the cytometric investigations were tested against the final diagnosis as the "gold standard" [18]. Similarly, the results of cytology were tested against the final diagnosis. The confidence intervals (CI) for the 95\% range were taken from the Geigy, Scientific Tables [19].

\section{Results}

\section{Control group}

ASC of both slides from each control subject were classified as benign or grade I in all but two cases. Normal slides contained inflammatory cells, epithelial cells and alveolar macrophages (fig. 1). All epithelial nuclei were found to be in the DNA-index range of $0.75-1.25$ and only single nuclei were found to deviate from the normal distribution, mainly as a small second peak with a DNA index close to 2.0. All but two samples from smokers were classified as benign (grade I) by ASC. Repeated ASC of the two subjects with suspicious samples produced benign results.

The quantitative evaluation of all samples derived from the control subjects led to a mean value of $0.122 \pm 0.022$ for $2 \mathrm{cDI}$ and $\mathrm{a} \mathrm{MG}$ of $0.080 \pm 0.014$. Comparing the sister slides of healthy subjects showed a mean difference of $2 \mathrm{cDI}$ values of $0.015 \pm 0.009$ 
a)

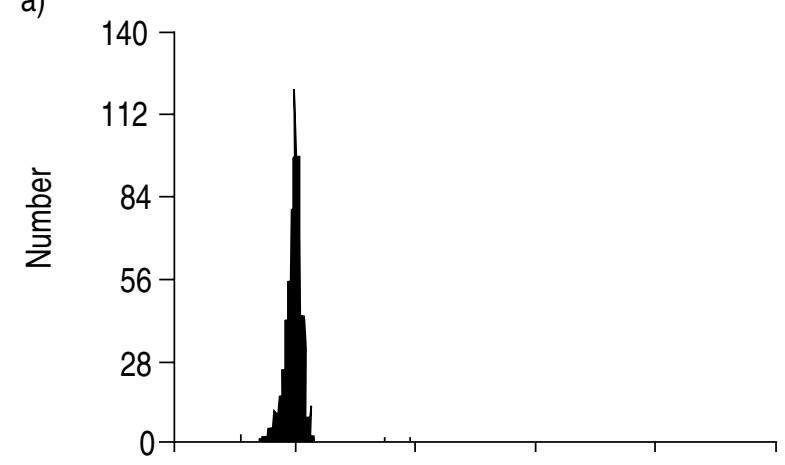

b)

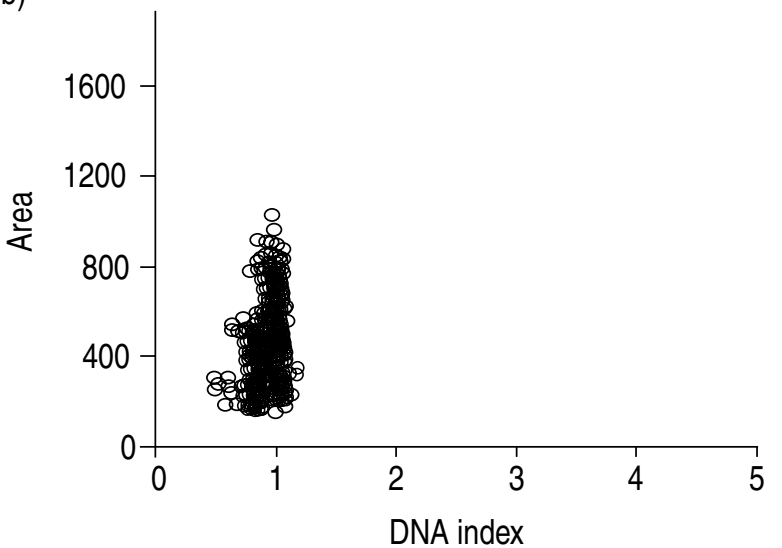

c)

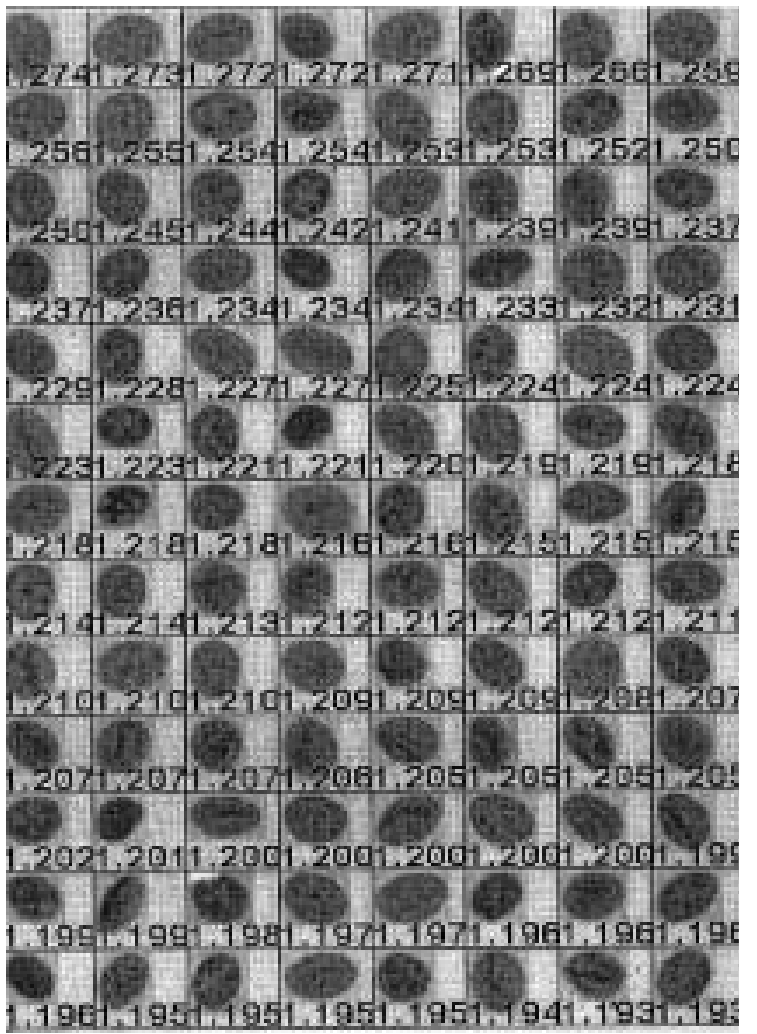

Fig. 1.-Result of semi-automated sputum cytometry (ASC) from a healthy control subject with normal values for the 2c-deviation index and malignancy grade. Report from ASC containing diagrams of a) deoxyribonucleic acid (DNA) distribution showing the frequency (number) of DNA index; b) correlation between DNA index and area, which is represented by the number of pixels within the frame (size $0.34 \times 0.34 \mu \mathrm{m})$; and c) a gallery of typical epithelial nuclei including the DNA index for each nucleus.

units (median 0.014) and led to identical grade I classifications.

Patients with silicosis, asbestosis andlor resected lung cancer

Figure 2 shows a suspicious ASC report from a sputum sample of a former uranium miner with silicosis, confirmed by CY as Pap IIID, moderate. In addition to the normal correlation between DNAamount and area, there were some "suspicious" nuclei in the DNA index range of 1.25-2.5, causing an increased 2cDI of 0.26 and a MG of 0.18 .

In a typical sputum sample from a patient with silicosis and a squamous epithelial lung cancer confirmed at the final diagnosis (fig. 3), numerous nuclei, exceeding 5c (5cER $3.7 \%)$ were found in addition to the suspicious nuclei in the DNA-index range of 1.25-2.5. The $2 \mathrm{cDI}$ increased to 0.46 and the $\mathrm{MG}$ increased to 0.21 .

Correlation between results from semi-automated sputum cytometry and outcome of conventional cytology

Cytologically investigated sputum samples from asymptomatic nonsmokers and heavy smokers were classified as normal (Pap I), mild, moderate or severe inflammatory (Pap II), and in rare cases as inflammatory with cellular metaplasia (Pap III). No evidence of neoplasia was found in chest radiographs or in the final diagnosis.

Among 404 occupationally-exposed patients, 20 cases of lung cancer or metastasis from other cancers were found at final diagnosis. Of the 384 patients without cancer, 323 were classified grade I by ASC, 55 as suspicious (grade II), two as highly suspicious (grade III), and four as inadequate (table 3). Among the 323 normal samples in ASC, 15 were inadequate on cytology, only one was classified as normal (Pap I), and the large majority (299) as mild, moderate or severe inflammatory (Pap II). Seven specimens contained dysplastic nuclei of different degrees (Pap IIID) and one nuclei of a CIS (Pap IV).

In 57 patients without lung cancer grade II and III cases seen on ASC, one was inadequate on cytology, two were Pap I, 21 were Pap II and another 10 included metaplasia. Dysplasia was seen in 18 cases and neoplasia in five samples. Hence, a total of 13 from 57 ASC-positive samples of patients without cancer at final diagnosis were considered pathological by cytology. Among patients with silicosis or asbestosis, 45 suspicious/highly suspicious samples were found using ASC. Twenty of these were classified by cytology as dysplasias, CIS or as invasive tumour (Pap 
a)

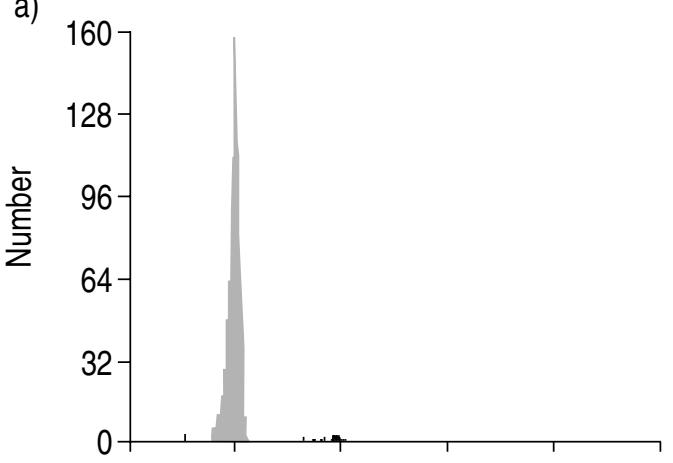

b)

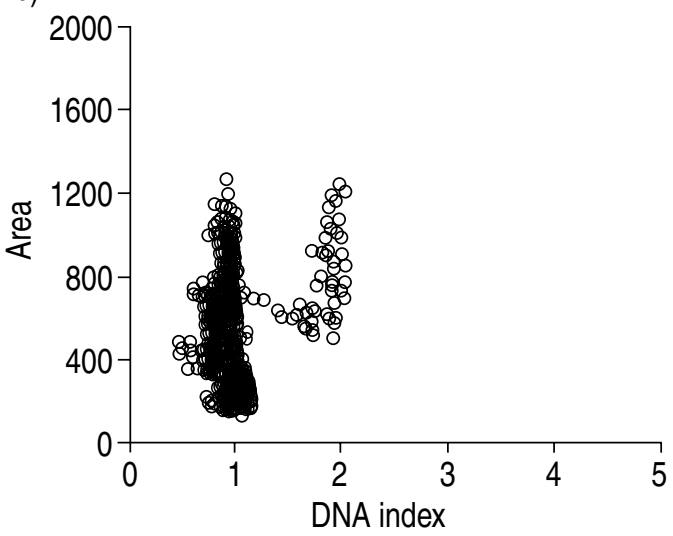

c)

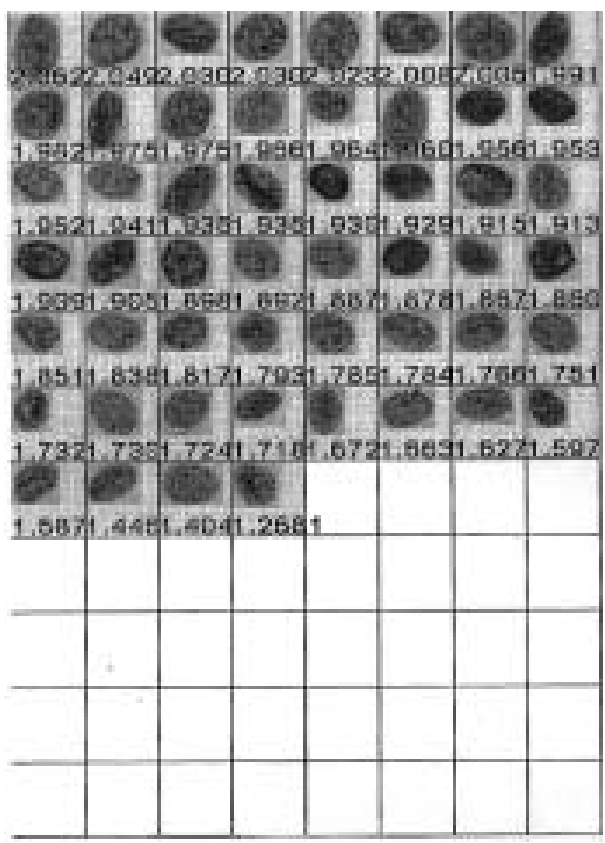

Fig. 2. - Suspicious result from semi-automated sputum cytometry (ASC) of a radon-exposed former uranium miner with pneumoconiosis, confirmed by cytology as moderate dysplasia (PapIIID, moderate) with numerous nuclei in the deoxyribonucleic acid (DNA)-index range 1.2-2.5. a) DNA distribution showing frequency (number) of DNA index; b) correlation between DNA index and area, which is represented by the number of pixels within the frame (size $0.34 \times 0.34 \mu \mathrm{m}$ ); and c) a gallery of typical epithelial nuclei including the DNA index for each nucleus.

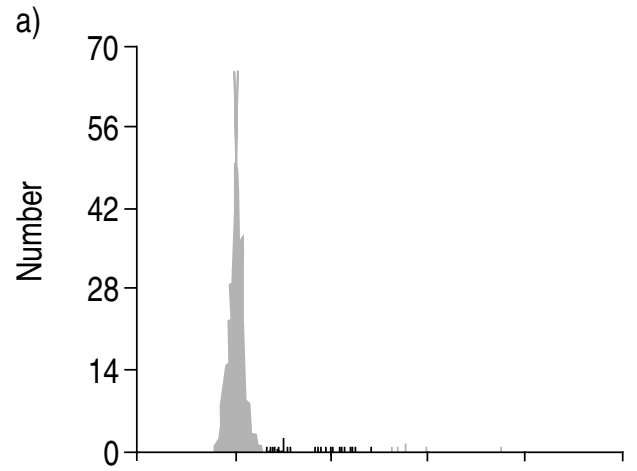

b)

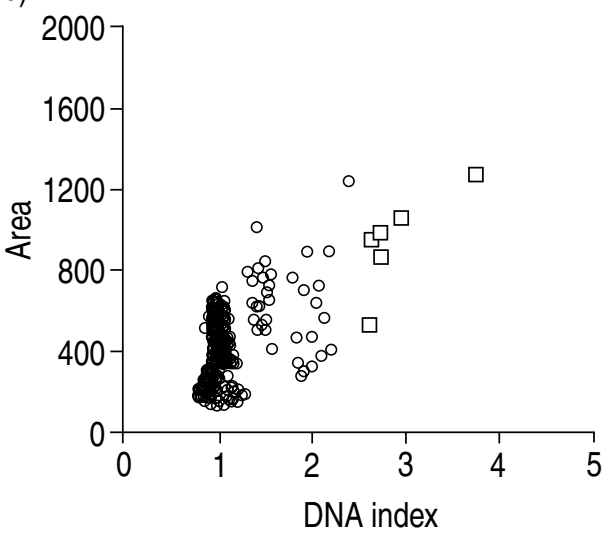

c)

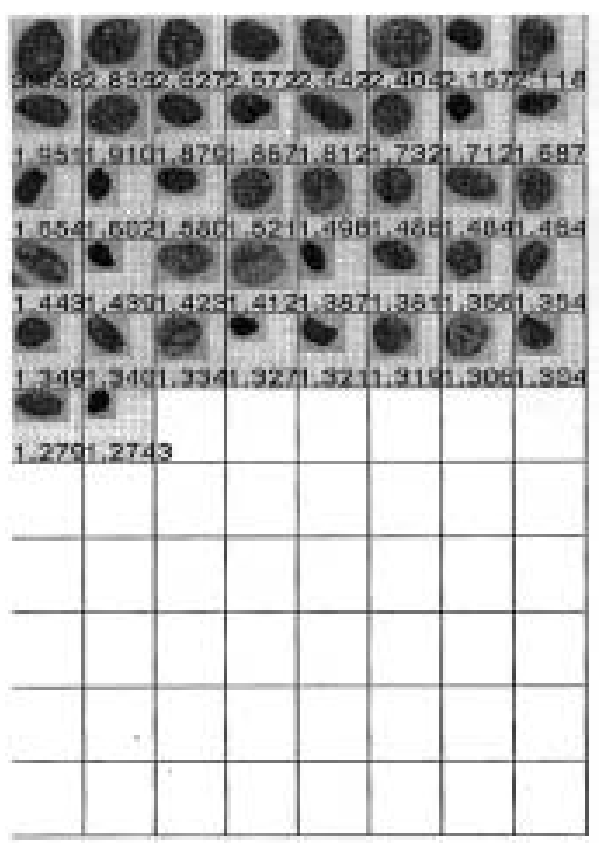

Fig. 3.- Highly suspicious cytometrical result from semi-automated sputum cytometry of a patient with squamous epithelial lung cancer, confirmed by cytology (Pap V) with numerous nuclei in the deoxyribonucleic acid (DNA)-index range 1.2-2.5 (O) and nuclei with DNA index $>2.5$ ( $\square$ ). a) DNA distribution showing frequency (number) of DNA index; b) correlation between DNA index and area, which is represented by the number of pixels within the frame (size $0.34 \times 0.34 \mu \mathrm{m}$ ); and c) a gallery of typical epithelial nuclei including DNA index for each nucleus. 
Table 3. - Results in patients with silicosis, asbestosis, and/or resected lung cancer without lung cancer diagnosis

\begin{tabular}{|c|c|c|c|c|c|c|}
\hline \multicolumn{2}{|c|}{ Cytometry } & \multicolumn{2}{|l|}{ Cytology } & \multicolumn{3}{|c|}{ Final diagnosis } \\
\hline Result & $\mathrm{n}$ & Result & $\mathrm{n}$ & Silicosis $n$ & Asbestosis $n$ & Lung resection $n$ \\
\hline \multirow[t]{3}{*}{ Grade 0} & 4 & Inadequate & 1 & 1 & & \\
\hline & & Pap I-III & 3 & 2 & 1 & \\
\hline & 323 & Inadequate & 15 & 10 & 5 & \\
\hline \multirow[t]{4}{*}{ Grade I } & & Pap I-III & 300 & 157 & 67 & 76 \\
\hline & & Pap IIID, mild & 6 & 1 & 4 & 1 \\
\hline & & Pap IIID, severe & 1 & 1 & & \\
\hline & & Pap IV & 1 & 1 & & \\
\hline \multirow[t]{7}{*}{ Grade II } & 55 & Inadequate & 1 & 1 & & \\
\hline & & Pap I-III & 31 & 14 & 10 & 7 \\
\hline & & Pap IIID, mild & 1 & 1 & & \\
\hline & & Pap IIID, moderate & 9 & 2 & 4 & 3 \\
\hline & & Pap IIID, severe & 8 & 5 & 2 & 1 \\
\hline & & Pap IV & 2 & 1 & 1 & \\
\hline & & Pap V & 3 & 1 & 1 & 1 \\
\hline Grade III & 2 & Pap I-III & 2 & 1 & 1 & \\
\hline
\end{tabular}

Pap: Papanicolaou classification. N=384. Grade 0: inadequate; grade I: benign; grade II: suspicious; grade III: highly suspicious.

IIID-V). The suspected cases of lung cancer were confirmed at final diagnosis. Among the samples from patients with previously resected lung cancer, in 12 cases a suspicious ASC result was obtained, five were also positive on $\mathrm{CY}$, and all were confirmed at final diagnosis as lung cancer. In total, 15 out of 20 samples of patients with lung cancer confirmed at final diagnosis were identified by ASC. False-positive results were obtained by ASC in 59 of 579 samples.

Lung cancer was found in 20 patients at final diagnosis. Six had asbestosis and 14 silicosis, and eight had had previous resections of lung cancer. Fourteen cancers were classified histologically as squamous cell lung cancer (SQuCLC), three as nonsmall cell lung cancer (NSCLC), two were adenocarcinomas, and one was an advanced pleural mesothelioma (table 4).

Sensitivity and specificity of semi-automated sputum cytometry

Compared to the final diagnosis based on all data available from 404 patients, 100 smokers and 100 controls, the sensitivity of ASC was $75.0 \%$ (15 out of 20) with a $95 \%$ CI of $50.9-90.3 \%$ (table 5). Specificity was $89.5 \%$ (520 out of 579 ), with a $95 \%$ CI of $78.3-96.1 \%$. The results of ASC represent a diagnostic efficiency of $89.3 \%$.

Table 4.-Results in patients with lung cancer diagnosis

\begin{tabular}{|c|c|c|c|c|c|}
\hline Patient no. & Cytometry grade & Cytology (Pap) & Lung disease & Histology & TNM classification \\
\hline 1 & $\mathrm{II}^{\#}$ & II & Asbestosis & SquCLC & T2,N0,M0 \\
\hline 2 & III $^{\bullet}$ & II & Asbestosis & SquCLC & T1,N0,M0 \\
\hline 3 & $\mathrm{II}^{\#}$ & IIID, severe & Asbestosis & Adeno & PMUBC \\
\hline 4 & $\mathrm{II}^{\#}$ & V & Asbestosis & Pleural mesothelioma & Advanced mesothelioma \\
\hline 5 & III $^{\bullet}$ & $\mathrm{V}$ & Asbestosis & SquCLC & $\mathrm{T} 2, \mathrm{~N} 0, \mathrm{M} 0$ \\
\hline 6 & $\mathrm{II}^{\#}$ & II & Asbestosis+Lu-Res & SQuCLC & $\mathrm{PT}^{f}{ }^{f}, \mathrm{~N} 1, \mathrm{M} 0$ \\
\hline 7 & $\mathrm{I}^{+}$ & V & Silicosis & SQuCLC & $\mathrm{T} 1, \mathrm{pN} 0^{f}, \mathrm{Mx}$ \\
\hline 8 & $\mathrm{II}^{\#}$ & IIID, severe & Silicosis & SQuCLC & $\mathrm{T} 2, \mathrm{~N} 3, \mathrm{M} 0$ \\
\hline 9 & $\mathrm{II}^{\#}$ & $\mathrm{~V}$ & Silicosis & SQuCLC & $\mathrm{T} 2, \mathrm{~N} 2, \mathrm{M} 0$ \\
\hline 10 & $\mathrm{II}^{\#}$ & $\mathrm{~V}$ & Silicosis & SQuCLC & $\mathrm{T} 2, \mathrm{~N} 0, \mathrm{M} 0$ \\
\hline 11 & III $^{\oplus}$ & $\mathrm{V}$ & Silicosis & SQuCLC & $\mathrm{T} 3, \mathrm{~N} 2, \mathrm{M} 1$ \\
\hline 12 & III $^{\oplus}$ & IV & Silicosis & SQuCLC & $\mathrm{T} 2, \mathrm{~N} 2, \mathrm{M} 0$ \\
\hline 13 & III" $^{\bullet}$ & V & Silicosis & non-SCLC & $\mathrm{T} 4, \mathrm{~N} 3, \mathrm{M} 1$ \\
\hline 14 & $0^{\S}$ & II & Silicosis+Lu-Res & SQuCLC & $\mathrm{pT} 2^{f}, \mathrm{~N} 0, \mathrm{M} 0$ \\
\hline 15 & $\mathrm{I}^{+}$ & II & Silicosis+Lu-Res & SQuCLC & $\mathrm{pT} 2^{f}, \mathrm{pN} 0^{f}, \mathrm{pM} 0^{f}$ \\
\hline 16 & $\mathrm{I}^{+}$ & II & Silicosis+Lu-Res & SQuCLC & $\mathrm{T} 2, \mathrm{~N} 0, \mathrm{M} 0$ \\
\hline 17 & $\mathrm{I}^{+}$ & II & Silicosis+Lu-Res & non-SCLC & PMUBC \\
\hline 18 & $\mathrm{II}^{\#}$ & III & Silicosis+Lu-Res & non-SCLC & $\mathrm{pT}^{f}{ }^{f}, \mathrm{pNx}^{f}, \mathrm{pMx}^{f}$ \\
\hline 19 & $\mathrm{II}^{\#}$ & $\mathrm{~V}$ & Silicosis+Lu-Res & SQuCLC & $\mathrm{T} 2, \mathrm{~N} 0, \mathrm{M} 0$ \\
\hline 20 & $\mathrm{II}^{\#}$ & V & Silicosis+Lu-Res & Adeno & $\mathrm{pT} 2^{f}, \mathrm{~N} 0, \mathrm{M} 0$ \\
\hline
\end{tabular}

Pap: Papanicolaou classification; TNM: tumour, node, metastasis; SQuCLC: squamous cell lung cancer; Adeno: adenocarcinoma; PMUBC: pulmonary metastasis from urinary bladder cancer; SCLC: small cell lung cancer; Lu-Res: lung resection. ${ }^{\#}$ : suspicious; ${ }^{\uparrow}$ : highly suspicious; ${ }^{+}$: benign; ${ }^{\S}$ : inadequate; ${ }^{f}$ : final results derived from pathology. $\mathrm{n}=20$. 
Table 5.-Evaluation of sensitivity and specificity of semi-automated sputum cytology (ASC) in the diagnosis of lung cancer

\begin{tabular}{lccccccc}
\hline & Sensitivity $\%$ & Specificity $\%$ & $\begin{array}{c}\text { Correct } \\
\text { positive }\end{array}$ & $\begin{array}{c}\text { False } \\
\text { positive }\end{array}$ & $\begin{array}{c}\text { False } \\
\text { negative }\end{array}$ & $\begin{array}{c}\text { Correct } \\
\text { negative }\end{array}$ & Inadequate \\
\hline Cytometry (ASC) & 75.0 & 89.8 & 15 & 59 & 5 & 520 & 5 \\
Cytology (CY) & 60.0 & 97.7 & 12 & 13 & 8 & 545 & 26 \\
Combination (ASC+CY) & 80.0 & 89.7 & 16 & 60 & 4 & 521 & 3 \\
\hline
\end{tabular}

The sensitivity of cytology was $60 \%$ (12 out of 20$)$ with a $95 \%$ CI of $36.1-80.9 \%$ and the specificity was as high as $97.3 \%$ (545 out of 558) with a $95 \%$ CI of 90.6-99.9\%.

The combination of ASC and cytology resulted in the detection of one more cases of lung cancer in group I (silicosis) and one false-positive case in group III (resected lung cancer). Thus, the combination of ASC and cytology had a greater sensitivity of $80 \%$ (16 out of 20) with a similar specificity of $89.6 \%$ (521 out of 581) and a diagnostic efficiency of $89.7 \%$.

\section{Discussion}

Quantitative semi-automated image cytometry of induced sputa, from radon-exposed former uranium miners with silicosis and workers with asbestosis, was shown to be sensitive and reliable in screening for lung cancer. Compared to the final diagnosis it was found that ASC had a sensitivity of 75\% (15 out of $20)$, which was higher than that of cytology $(60 \%$ or 12 out of 20). ASC-specificity (89.8\%) was lower than cytology (97.3\%). The combination of ASC and cytology resulted in an increased sensitivity $(80 \%$ or 16 out of 20) with insignificant loss of specificity (89.7\%). The results obtained represent a diagnostic efficiency of $89.3 \%$ for ASC and suggest that ASC would be an effective tool for a screening programme for lung cancer in high-risk groups. Among 404 patients, 72 samples suspicious for malignancy were found by ASC, 13 confirmed as Pap V, and 11 confirmed as severe dysplasia by cytology. In the final diagnosis, 20 tumours were reported, 15 of which were detected by ASC. From the control group, only one of the sister slides from each of two smokers were suspicious by ASC initially, but found to be normal on repeat ASC.

Presently, considerable research is being carried out on sputum samples, bronchial washings and brushings using genetic and other markers for early lung cancer $[20,21]$. Using microsatellite markers, genetic alterations in bronchial-lavage cells were detected in 35\% ( 15 out of 43 ) of patients with lung cancer, but also in $23 \%$ (11 out of 43 ) of patients without evidence of neoplasia [22]. In bronchial brushings from patients with lung cancer, loss of heterozygosity in at least one chromosomal locus was present in $79 \%$, whereas cytology was positive in only 59\% [21]. Microsatellite alterations were found in $49 \%$ (25 out of 51) in tumour, normal bronchial mucosa and cytological specimens from patients with lung cancer [20]. A number of mutations have been found in lung cancer such as allelic deletions of tumour-suppressor genes or the presence of $\mathrm{p} 53$ alterations not only in lung cancer [23]. Other approaches include specific monoclonal antibodies for recognition of human lung cancer antigen on sputum cells [24]. These ongoing studies are in an experimental stage and must still be validated clinically.

With few exceptions, sputum induction by inhalation of aerosolized 3\% saline mobilized sufficient diagnostic cells from the lower airways. Only five of 604 samples contained insufficient material for adequate ASC and 26 were inadequate for cytology, in that they contained numerous buccal cells, but too few alveolar macrophages and columnar cells. Even in a healthy, nonchronic obstructive pulmonary disease population, saline induction gave adequate results in $>80 \%$ of subjects [25]. Compared to the quality of spontaneous sputum, induction with 3\% saline mobilized sufficient sputum from the lower airways [10] and should be preferred to spontaneous sputum samples.

Treatment with $0.1 \%$ DTT resulted in complete liquefaction of sputum specimens $[9,10]$. Samples sent through the mail reaching the authors' laboratory could be processed directly, either with the MARATHON-S or manually. In either mode, the pellet is resuspended in Saccomanno's fixative depending on the size and smeared on glass slides similar to blood smears without shear forces altering the cellular integrity. This procedure should result in an even distribution of diagnostic cells on all slides, which can not be obtained with the conventional "pick and smear" or even with the "blending-method" used by SACCOMANNo et al. [26]. The largely automated procedure could have contributed to the small number of inadequate samples; manual processing is preferable in samples at extremes of too few or too many cells.

In a study revisiting 60 representative studies to assess the sensitivity of sputum cytology [27], an average sensitivity of $64.5 \%$ with a range of $22.0-98.1 \%$ was calculated. The reviewers' own results showed a sensitivity of $40.3 \%$ for sputum cytology [27], which was comparable to earlier reports in the literature [5], but not as exceptionally high as the sensitivity of sputum cytology reported by BöcKING et al. [28], who used a combination of cytology on three separate samples, quantitative cytometry and immunohistochemistry (paraffin-embedded sputum).

Compared to earlier studies for cytological evaluation of sputum samples, bronchial washings or brush biopsies for the diagnosis of bronchopulmonary tumours, the present results with the automated cytometer had a higher sensitivity [1]. DE GARCIA et al. [29] found a sensitivity of $33 \%$ for the investigation of 
bronchial washings and $56 \%$ for the combination of bronchial washings with bronchoalveolar lavage and postbronchoscopy sputum. PirozYnski [30] reported a sensitivity of $64 \%$ in a comparable study. Several authors describe the dependence of the sensitivity of cytologically investigated sputa and bronchial washings on tumour location and size [27, 30]. A parallel investigation of endoscopic findings in 142 patients with suspected bronchopulmonary tumours showed the following growth patterns: $22 \%$ mainly submucosal tumour growth, $44 \%$ exophytic tumours localized in the visual range, $11 \%$ peripheral lesions not visible with bronchoscopy [1]. In the present study on bronchial washings, a higher positive identification rate in cases with bronchoscopically visible tumours ( $84 \%$ for submucosal, and $90 \%$ for exophytic tumour growth) was found. Without visible endoscopic changes, ASC could identify suspicious nuclei in $56 \%$ of the cases with peripheral lesions [1].

It could be speculated that a certain proportion of the ASC and cytology "false-positive" results represent early oncogenetic changes not detectable by present means. Some ASC-positive results correspond to cytologically-classified dysplasia of different degrees (mild, moderate, or severe) and even to epithelial metaplasia, which are thought to be largely reversible. With the possibility of identifying these potential preneoplastic lesions, more knowledge about the natural history of carcinogenesis may be acquired in the course of time. Inflammatory alterations of nuclear structure may also lead to misinterpretation. An altered decision threshold will have to be tested, together with careful follow-up of patients without confirmed tumour but with suspicious cytometry/ cytology results.

Interpretation of ASC classification (in its present version) does not depend solely on $2 \mathrm{cDI}$ and $\mathrm{MG}$, but to a lesser degree, it also depends on the morphological, nonquantifiable impression derived from the gallery of abnormal nuclei presented by the cytometer. A receiver operator curve (ROC) would not represent the true potential of this method. Almost $20 \%$ of the suspicious cases of ASC contained nuclei, more or less suspicious for dysplasia or malignancy without a $2 \mathrm{cDI}$ $>0.20$. One of the most important further developments of ASC will be a sample classifier, giving one integrative score for normal and abnormal samples, based on a couple of nuclear features differentiating normal from pathological nuclei. Features such as variation area, variation intensity, fractal area, variation radius or long-45 runs may characterize pathologically transformed nuclei [16]. They can be integrated into a sample classifier for sputum and it will then be possible to draw ROCs. It is possible that future developments of ASC may allow for the identification of histologically distinct tumour types (SCLC, SQuCLC, adenocarcinoma, heterogeneouslydifferentiated tumour or metastases of nonprimary lung cancers).

In patients with cytology findings Pap IIID severe and higher, investigations were initiated; in cases of IIID mild and moderate dysplasia, a second sputum sample was requested. Analysis of sputa classified by ASC as suspicious or highly suspicious without cytological evidence for pathology should be repeated immediately.

With samples persistently classified as suspicious or highly suspicious by ASC and confirmed by cytology as severely dysplastic or higher, subjects should be recommended for endoscopy and radiological investigation. In cases where no tumour or preneoplasia is detected, sputum investigations should be repeated at 6-monthly intervals until either spontaneous remission or neoplastic changes occur. Follow-up of severe dysplasia, found in sputum samples, demonstrated malignancy in $46 \%$ of the cases in one series [30]. SACCOMANNo et al. [25], investigating sputum from uranium miners who developed lung cancer with follow-up over $10 \mathrm{yrs}$, detected atypia consistent with severe dysplasia in $60 \%$ of the cases on initial investigations and squamous cell cancer was found to develop in $83 \%$ of these in the course of time.

In conclusion, based on the present limited findings, semi-automated sputum cytometry appears to be a sensitive noninvasive method for detection of malignant, and possibly premalignant, changes in the respiratory tract. Compared to other methods, it provides automated, attendant-free and standardized cell collection and enables interactive interpretation of the results. Patients with persistent suspicious semiautomated sputum cytometry findings should undergo further diagnostic tests including, at least, conventional cytology. With standardized sputum processing and time saving automation, semi-automated sputum cytometry in combination with other diagnostic tests may be useful in the near future for screening highrisk groups of patients, such as occupationally-exposed workers or heavy smokers. It is already an essential element in the prospective Research Institute for Diagnosis and Treatment of Early Lung Cancer large scale feasibility study of early lung cancer detection in high-risk patients.

\footnotetext{
Acknowledgements. The authors wish to express their gratitude to B. Palcic of the British Columbia Cancer Agency for his pioneering work in developing the Cyto-Savant and his support in establishing the system at the RIDTELC unit in Bochum.
}

\section{References}

1. Marek W, Krampe S, Dickgreber NJ, et al. Automatisierte quantitative Image-Zytometrie bronchialer Spülflüssigkeiten bei Verdacht auf broncho-pulmonale Tumoren: Vergleich mit Zytologie, Histologie und klinischer Diagnose. Pneumologie 1999; 53: 583-559.

2. Khanavkar B, Gnudi F, Muti A, et al. Grundlagen der LIFE-Autofluoreszenzbronchoskopie. Pneumologie 1998; 52: 71-76.

3. Chmelevsky D, Barclay D, Kellerer AM, Tomasek L, Kunze KD, Placek V. Probability of causation for lung cancer after exposure to radon progeny: a comparison of models and data. Health Phys 1994; 67: 15-23.

4. Samet MS, Pathak DR, Morgan MV, Coultas DV, James DS, Hunt WC. Silicosis and lung cancer risk in 
underground uranium miners. Health Phys 1995; 6: 617-624.

5. Flehinger BJ, Melamed M, Zaman MB, Heelan R, Perchick WB, Martini N. Results of the initial (prevalence) radiologic and cytologic screening in the Memorial Sloan Kettering Study. Am Rev Respir Dis 1984; 130: 555-565.

6. Fontana RS, Sanderson DR, Woolner LB, et al. Screening for lung cancer: a critique of the Mayo Lung Project. Cancer 1991; 67: 1155-1164.

7. Tockman MS. Survival and mortality from lung cancer in a screened population: The Johns Hopkins Study. Chest 1986; 89: Suppl., 324S-325S.

8. Kubik A, Polak J. Lung cancer detection: Results of a randomized prospective study in Czechoslovakia. Cancer 1986; 57: 2428-2430.

9. Nielsen L, Marek W, Köhler C, Khanavkar B, Muti A, Nakhosteen JA. Improvement of sputum preparation for automated cytometry by treatment with 0.2\% Dithiothreitol (DTT). Eur Respir J 1998; 12: Suppl. 28, S248.

10. Tang CS, Tang CM, Lau YY, Kung IT. Sensitivity of sputum cytology after homogenization with dithiothreitol in lung cancer detection. Two years of experience. Acta Cytol 1995; 39: 1137-1140.

11. Papanicolaou GN. A new procedure for staining vaginal smears. Science 1942; 95: 438-439.

12. Schulte E, Wittekind DH. Standarization of the Feulgen reaction: the influence of chromatin condensation on the kinetics of acid hydsrolysis. Anal Cell Pathol 1990; 2: 149-157.

13. Papanicolaou GN. Atlas of exfoliative cytology. Cambridge, Harvard University Press, 1954.

14. Garner D, Harrison A, MacAulay C, Palcic B. CytoSavant(TM) and its use in automated screening of cervical smears. In: Wied GL, Bartels PH, Rosenthal DL, Schenck U, eds. Compendium on the Computerized Cytology and Histology Laboratory. Chicago, IL, Tutorials of Cytology, 1994; pp. 346-352.

15. Böcking A, Giroud F, Reith A. Consensus report of the ESACP task force on standardization of diagnostic DNA image cytometry. Anal Cell Pathol 1995; 8: 67-74.

16. Doudkine A, MacAulay C, Poulin N, Palcic B. Nuclear texture measurements in image cytometry. Pathologica 1995; 87: 286-299.

17. Böcking A, Adler CP, Common $\mathrm{HH}$, Hilgarth $\mathrm{M}$, Granzen B, Auffermann W. Algorithm for a DNAcytophotometric diagnosis and grading of malignancy. Anal Quant Cytol 1984; 6: 1-8.
18. Sachs L, Sachs L. Angewandte Statistik. Anwendung statistischer Methoden. Berlin, Heidelberg, New York, Springer Verlag, 1992; pp. 1-864.

19. Wissenschaftliche Tabellen Geigy. Statistik. 8th Edition. Basel, Chiba-Geigy, 1980.

20. Miozzo M, Sozzi G, Musso K, et al. Microsatellite alterations in bronchial and sputum specimens of lung cancer patients. Cancer Res 1996; 56: 2285-2288.

21. Powell CA, Klares S, O'Connor G, Brody JS. Loss of heterozygosity in epithelial cells obtained by bronchial brushing: clinical utility in lung cancer. Clin Cancer Res 1999; 5: 2025-2034.

22. Field JK, Liloglou T, Xinarianos G, et al. Genetic alterations in bronchial lavage as a potential marker for individuals with high risk of developing lung cancer. Cancer Res 1999; 59: 2690-2695.

23. Beoers JE, Ten Velde GPM, Thunnissen BJM. p53 in squamous metaplasia: a marker for risk of respiratory tract carcinoma. Am J Respir Crit Care Med 1996; 153: 411-416.

24. Tockman MS, Gupta P, Myres JD, et al. Sensitive and specific monoclonal antibody recognition of human lung cancer antigen on preserved sputum cells: a new approach to early lung cancer detection. J Clin Oncol 1988; 6: 1685-1693.

25. Belda J, Leigh R, Parameswaran K, O'Byrne P, Sears MR, Hargreave FE. Induced sputum cell counts in healthy adults. Am J Respir Crit Care Med 2000; 161: 475-478.

26. Saccomanno G, Saunders RP, Ellis H, Archer VE, Wood BG, Beckler PA. Concentration of carcinoma or atypical cells in sputum. Acta Cytol 1963; 7: 305-310.

27. Sing A, Freudenberg N, Kortsik C, Wertzel H, Klosa B, Hasse J. Comparison of the sensitivity of sputum und brush cytology in the diagnosis of lung carcinomas. Acta Cytol 1997; 41: 399-408.

28. Böcking A, Biesterfeld S, Chatelain R, Gien-Gerlach G, Esser E. Diagnosis of bronchial carcinoma on sections of paraffin-embedded sputum: sensitivity and specificity of an alternative to routine cytology. Acta Cytol 1992; 36: 37-47.

29. de Garcia J, Bravo C, Miravitelles M, et al. Diagnostic value of bronchoalveolar lavage in peripheral lung cancer. Am Rev Respir Dis 1993; 147: 649-652.

30. Pirozynski M. Bronchoalveolar lavage in the diagnosis of peripheral, primary lung cancer. Chest 1992; 102: 372-374.

31. Risse EK, Vooijs GP, van't Hof MA. Diagnostic significance of "severe dysplasia" in sputum cytology. Acta Cytol 1988; 32: 629-634. 